\title{
Review of Recent Legacy Airline Mergers in the U.S.: An Empirical Study from Investors' Perspectives
}

\author{
Carol C. Huang \\ Western Connecticut State University \\ Chris C. Hsu \\ CUNY Aviation Institute at York College \\ Triant Flouris \\ Hellenic American University
}

Since the 2008 financial crisis, three legacy airline mergers have dramatically reshaped the landscape of the U.S. airline industry. Due to the lengthy process involved in an airline merger, it is important to understand whether the investors view the merger favorably. This study examined how investors reacted to the three recent legacy airline mergers in the U.S. by adopting a GARCH-EVT-Copula approach. Our empirical results revealed that positive dependencies between returns and trading volume changes were observed for each merger during various periods, indicating that investors were optimistic about the mergers. Accordingly, implications for future mergers are discussed.

\section{INTRODUCTION}

The Airline Deregulation Act of 1978 was introduced to promote efficiency in the U.S. airline industry by enabling competition. As new airlines entered the market and the U.S. airline industry became more competitive, the public enjoyed lower airfares and higher standards of quality. However, this fierce competition made it difficult for airlines to maintain their operations, as the industry is highly capital intensive and very sensitive to economic fluctuations, which inevitably led to a wave of mergers to improve a company's operation and maintain its presence.

Since the early 2000s, the U.S. airline industry has seen many mergers. Among those, three legacy airline mergers reshaped the structure of the industry: the merger of Northwest Airlines and Delta Air Lines, the merger of United Airlines and Continental Airlines, and the merger of American Airlines and US Airways. In an airline merger, an acquiring company chooses its target company for two major reasons: to buy out a competitor or inherit the target company's market. Together, these acquiring airlines, American Airlines, Delta Air Lines, and United Airlines, manage most of today's US air-travel market.

Mergers in the airline industry always attract a lot of attention not only because the capital involved is usually pronounced, but also because these mergers are challenged by difficulties in various integrations, regulation compliance, and approvals from authorities, all of which bring about high uncertainty in the 
likely outcome. As Manuela, Rhoades, and Curtis (2016) documented, airline mergers are not always promising. Out of 20 major airline mergers from 1978 to 2005, only one was considered successful in terms of operational efficiency and financial performance. While perspectives on evaluating the outcome of a merger differ, from the investors' perspectives the prominent question is whether the merger will add value to shareholders.

The objective of this study was to examine whether investors held a favorable view of the recent legacy airline mergers in the U.S. from one month before the merger announcement to one month after the merger completion. The hypothesis stated that if investors expect that post-merger operations will generate higher revenue, they will actively trade the acquiring company's stocks to take advantage of stock price appreciation in the future. Since the return-volume relation suggests that the returns and volume are correlated, we investigated the dependencies between changes in trading volume and stock returns of the acquiring companies to assess investors' perspectives. Given that the fat-tail exhibits on stock return distributions, instead of the Pearson's parametric correlation analyses, we adopted GARCHEVT-Copula models to capture time-varying dependencies. Specifically, we employed a GARCH $(1,1)$ model to convert raw data to become independent and identically distributed (i.i.d.) to satisfy the assumptions of the copula models. In addition, Extreme Value Theory (EVT) was used to model the fattail of the data distributions. Three copula models, Student's $t$, Clayton, and Gumbel copula, were utilized in this study. The Student's $t$ copula was used to estimate positive and negative dependencies between changes in trading volume and stock returns. To focus on investors' reactions on a specific side of the distribution, we included Clayton and Gumbel copulas. The former was adopted to capture extreme dependencies on the left tail (negative side) while the latter was used to examine extreme dependencies on the right tail (positive side). Since positive dependencies can be observed under two scenarios (i.e., simultaneously increases or decreases in both stock returns and changes of trading volume), the results from the three copulas were consolidated to reach comprehensive findings. Thus, if significant positive dependencies from the Student's $t$ copula and significant dependencies from the Gumbel copula were observed during the same period, we could claim that investors held a favorable view of the merger. However, if significant positive dependencies from the Student's $t$ and Clayton copulas were observed, but no significant dependencies were observed from the Gumbel copula over the same period, we could conclude that investors, as reflected in their trading, were not in favor of the merger.

The empirical findings of this study indicated that daily changes in trading volume and stock returns showed positive dependencies for all acquiring companies during the periods studied. This suggests that investors had favorable expectations concerning the outcomes of the mergers. Regarding the tail behaviors, dependencies on the right tails from the Gumbel copula model overlapped with positive dependencies from the Student's $t$ copula, indicating the confidence displayed by investors in these mergers. Very weak dependencies were observed in the left tails from the Clayton copula model. This suggests that the declines in stock prices were not associated with significant declines in trading volume. Although the records of the successful airline mergers are rare (King et al., 2004; US GAO, 2010), our empirical findings showed that investors developed positive outlooks of post-merger revenue following the expectation that the recent legacy airline mergers would transform the industry to an oligopoly, supporting the argument suggested by Hazel (2018) that airline consolidation of limited capacity will benefit airline revenue. While extensive studies have analyzed the subject of airline mergers, few studies have examined the issue from investors' perspectives, and the studies on the more recent mergers are still developing. As stated in Carlton, Israel, MacSwain, and Orlov (2019), studies on more recent mergers are still inconclusive, and whether these recent mergers had a pro-competitive or anti-competitive effect on consumers is an ongoing debate. The empirical results herein add to the literature by clarifying investors' perspectives of these merger events, thereby, providing policy implications for airline strategic decisionmakers and investors and contributing to the current understanding of airline mergers.

The remainder of the paper is organized as follows. Section 2 reviews the literature on mergers in the airline industry. Section 3 discusses the empirical methodologies, and Section 4 describes the data. Section 5 reports the empirical results, and Section 6 concludes the paper. 


\section{LITERATURE REVIEW}

Mergers are complicated corporate events. Mergers in regulated industries, like the airline industry, face more challenges compared to those in other industries. Morrison (1996) conducted a long-run analysis of three airline mergers and concluded that some of the mergers can lead to substantial fares increase. Cox and Portes (1998) pointed out that merger process in regulated industries tends to be longer and the market's assessment of the probability of concluding a successful deal varies as the negotiation between the parties evolves. Therefore, using a shorter time horizon to analyze the potential effect of a merger may result in estimation errors. Other studies on earlier airline mergers include Slovin et al. (1991), Kim and Singal (1993), Singal (1996), Peters (2006), Berry and Jia (2010), and others.

From the perspectives of synergy creation, the study of Brueckner and Pels (2005) examined the merger of Air France and KLM. The empirical outcomes of this study implied that airlines would benefit from higher profits after a merger while passengers would suffer from a social welfare reduction. Merkert and Morrell (2012) analyzed 66 airline mergers with the Data Envelopment Analysis (DEA) model to determine if, indeed, "bigger was better." Their empirical outcomes suggested that running a super-sized airline may not be efficient. To maintain efficiency, the optimal size of an airline would have an available seat kilometer (ASK) capacity between 34 and 53 billion. Raghavan (2013) investigated synergies created by the Delta Air Lines and Northwest Airlines merger and found that although the 1978 deregulation brought more competition, it did not improve airline efficiency. Kawamori and Lin (2013) analyzed whether a merger between a legacy airline with hub-to-hub operations and a low-cost carrier with pointto-point operations would benefit the airline. Their study suggested that the profits would improve by removing one-stop services with large operating costs and nonstop services with small operating costs. Schosser and Wittmer (2015) reported that geographical differences exist in synergy realization. In general, airline mergers in Europe had lower cost synergies and lower synergy estimations compared to airline mergers in North and Latin Americas. Additionally, airline mergers in the Americas expected more revenue rather than cost synergies. Hazel (2018) used U.S. airlines revenue per available seat mile (RASM) data from 1995 to 2016 to investigate the relationship between U.S. domestic airline capacity and airline revenue. The results indicated that airline revenue depends on the capacity change of the entire airline industry, not on the capacity change of an individual airline. Therefore, airline consolidation of limited capacity would benefit airline revenue. In another study, Carlton, Israel, MacSwain, and Orlov (2019) utilized difference-in-difference regression analysis to investigate recent legacy airline mergers and suggested that these mergers had a pro-competitive effect on consumers.

Regarding the financial market's responses to airline mergers, Flouris and Swidler (2004) examined the reaction of the financial market to the merger announcement of American Airlines and Trans World Airlines (TWA). Their findings indicated that market players were not in favor of the merger and that rumors of the merger circulating in the financial market triggered American Airlines stock to drop two days before the merger was officially announced. Gong and Firth (2006) used the data from 1985 to 2001 to analyze the effect of U.S. airline mergers on the stock market. Their study found that stock market practitioners were interested in investing in the target airlines but not in their rivals on the merger announcement dates, and no significant proof was found to support the claims that market investors were reacting to the acquiring airlines on the merger announcement dates. Cortés, García, and Agudelo (2015) studied the mergers and acquisitions in the Latin American airline industry and concluded that the shareholders of some target companies benefit from obtaining positive abnormal returns after the announcement of a merger. The potential effect on the shareholders of the acquiring companies is, however, inconclusive. Manuela, Rhoades, and Curtis (2016) evaluated the post-merger performance of US. Airways Group after it merged with American West Airlines in 2005. Their findings demonstrated that the ability of the merged company to pay its obligations had improved, although the financial ratios were not significantly better after the merger. Hsu and Flouris (2017) studied three recent European airline mergers: Air France-KLM, Iberia-British Airways, and Lufthansa. Their empirical results indicated that, in general, investors were in favor of the mergers and that positive dependencies existed between changes in trading volume and stock returns during the merger announcement periods. 


\section{METHODOLOGIES}

The return-volume relation is an important dynamic in financial markets. As indicated in Karpoff (1987), return-volume relation offers many insights into the financial markets, ranging from the structure of the financial markets to the information contents of the arrival of an event. In many empirical studies, returns were considered as the market's assessment of new information and the volume was treated as an indicator of whether investors support the coming of the information. To analyze investors' perceptions of the recent legacy airline mergers, we explored the dynamic dependencies between stock returns and trading volume changes over each of the airline merger periods. To do so, we first defined continuous stock returns and trading volume changes of the airlines as follows:

$\mathrm{p}_{i, t}=\mathrm{LN}\left(\frac{\mathrm{s}_{\mathrm{i}, \mathrm{t}}}{\mathrm{s}_{\mathrm{i}, \mathrm{t}-1}}\right)$

where $\mathrm{s}_{i, t}$ represents the stock price of airline $i$ on date $t$ and $\mathrm{s}_{i, t-1}$ refers to the stock price of airline $i$ on date $(t-1)$. The daily continuous stock return of airline $i$ on date $t, p_{i, t}$, is defined as the natural logarithmic difference between airline $i$ 's stock price on date $t$ and the previous business day, (t-1). Based on this concept, the continuous change of airline $i$ 's stock trading volume can be defined as:

$q_{i, t}=\mathrm{LN}\left(\frac{w_{i, t}}{w_{i, t-1}}\right)$

where $q_{i, t}$ stands for the continuous change of stock trading volume of airline stock $i$ on day $t$ and $w_{i, t}$ and $w_{i, t-1}$ represent the trading volume of airline stock $i$ on date $t$ and date $(t-1)$, respectively.

The GARCH-EVT-Copula model suggested by Hsu, Huang, and Chiou (2012) was adopted in this study. Copula models are commonly used in financial risk modeling to fit non-normal distributed data and have been used in studying the dependence between block delays and gate arrival delays at major U.S. airports (Diana, 2011). The strength of copula models is that they release the normality assumption of the data distribution. Since copula models require data to be in an independent and identically distributed (i.i.d.) sequence, we used the $\operatorname{GARCH}(1,1)$ model to transform the original changes in trading volume and stock returns to extract i.i.d. sequences. According to Engle $(2002)$, the GARCH $(1,1)$ model is expressed as:

$\delta_{i, t}=\omega_{i, t}+\varepsilon_{i, t}$

$\varepsilon_{i, t}=y_{i, t} \sigma_{i, t}$

$y_{i, t} \sim i i d, E\left(y_{i, t}\right)=0$ and $V\left(y_{i, t}\right)=0$

and $\sigma_{i, t}^{2}=\vartheta+\varphi_{i} \varepsilon_{i, t-1}^{2}+\tau_{i} \sigma_{t-1}^{2}$

where $\delta_{i, t}$ stands for the actual values of $p_{i, t}$ and $q_{i, t}$, respectively. $\delta_{i, t}$ is defined as the combination of its mean $\omega_{i, t}$ plus the error term $\varepsilon_{i, t}$. The error term $\varepsilon_{i, t}$, can be split into a stochastic process, $y_{i, t}$, and a timedependent standard deviation, $\sigma_{i, t}$. The random variable $y_{i, t}$ is a white noise process with the expected value and the variance equal to 0 . The time-dependent standard deviation, $\sigma_{i, t}$, is a one-lag generalized autoregressive process of the error term with the parameters $\varphi$ and $\tau$. With the results of equations (1) and (2), we were able to derive $\sigma_{i, t}$ and $\omega_{i, t}$, and to filter out the original data to obtain the independent and identically distributed (i.i.d.) sequence, $y_{i, t}$.

Owing to the fact that fat-tails are often observed in financial data, the uniform distribution of the i.i.d. data may not be able to precisely represent the distribution tails. To address this problem, we adopted the extreme value theory as suggested by Beirlant, Goegebeur, Segers, and Teugels (2004) with 
the generalized Pareto distribution to model the distribution tails. Thus, our data distributions became semi-parameter distributions with the uniform distribution (no parameter) to model the distribution center and the generalized Pareto distribution (with parameters) to model the distribution tails. As indicated by Hsu, Huang, and Chiou (2012), the above i.i.d. sequence, $y_{i, t}$, can be described as follows:

$$
F_{i}\left(\widehat{y}_{l}\right)=\left\{\begin{array}{c}
\frac{g_{l}}{n}\left[\widehat{\lambda}_{l}^{l} \frac{\theta_{i}^{l}-y_{i}}{\alpha_{i}^{l}}\right]^{\frac{-1}{\lambda_{i}^{l}}}, \text { for } y_{i}<\theta_{i}^{l} \\
\varphi\left(\widehat{y}_{l}\right), \text { for } \theta_{i}^{l}<y_{i}<\theta_{i}^{r} \\
1-\frac{g_{r}}{n}\left[\widehat{\lambda_{l}^{r}} \frac{y_{i}-\theta_{i}^{r}}{\alpha_{i}^{r}}\right]^{\frac{-1}{\lambda_{i}^{r}}}, \text { for } y_{i}>\theta_{i}^{r}
\end{array}\right.
$$

where $\alpha$ is the scale parameter, $\lambda$ is the shape parameter, $n$ is the number of observations, $g_{l}$ stands for the number of observations below the threshold $\theta_{i}^{l}$, and $g_{r}$ stands for the number of observations above the threshold $\theta_{i}^{r}$. The threshold $\theta_{i}$ was used to distinguish extreme values, and the superscripts of $l$ and $r$ of $\theta_{i}$ denoted the threshold of left and right tails, respectively. We defined the extreme values as those of the upper $5 \%$ or the lower $5 \%$ of the observations, as suggested by Neftci (2000).

Although Sklar (1959) first introduced copula models in the field of statistics, they have been widely adopted in the field of finance since the 1990s. According to Embrechts, Lindskog, and McNeil (2003), the fundamental theory of the multivariate copula models demonstrates that for a series of random vectors $\left(A_{1}, A_{2}, A_{3}, \ldots, A_{n}\right)$, as long as their marginal distributions, $M_{1}, M_{2}, \ldots, M_{n}$, are continuous, there will be a unique copula function $C$, represented as $F\left(A_{1}, A_{2}, \ldots, A_{n}\right)=C\left(M_{1}\left(A_{1}\right), M_{2}\left(A_{2}\right), \ldots, M_{n}\left(A_{n}\right)\right)$. For a two-variable model, such as the one in this study, we can rewrite the previous equation as $F\left(A_{i}, B_{i}\right)=$ $C\left(M_{i}\left(A_{i}\right), M_{i}\left(B_{i}\right)\right)$, where $\mathrm{A}_{i}$ is the vector of the semi-parameter distribution that was extracted from the original stock returns of the airlines $i$ through equation (7), and $\mathrm{B}_{i}$ is the vector of the semi-parameter distribution extracted from stock trading volume changes of airline $i$ through equation (7).

In this study, three widely-used copula models (the Student's $t$ copula, Gumbel copula, and Clayton copula) were utilized. The Student's $t$ copula model was derived from the symmetrical Student's $t$ distribution with the tails that were fatter compared to those of the normal distribution. The Student's $t$ copula can be defined as follows:

$C_{g, \rho}^{t}\left(M_{A_{i}}, M_{B_{i}}\right)=\int_{-\infty}^{\mathrm{t}^{-1}\left(M_{A_{i}}\right)} \int_{-\infty}^{\mathrm{tg}^{-1}\left(M_{B_{i}}\right)} \frac{1}{2 \pi \sqrt{1-\rho^{2}}}\left\{1+\frac{s^{2}-2 \rho s t+t^{2}}{g\left(1-\rho^{2}\right)}\right\}^{-\frac{(g+2)}{2}} d s d t$

where $M_{A_{i}}$ and $M_{B_{i}}$ represent the marginal distribution of the daily stock returns and daily stock trading volume changes of airline $i . t_{g}^{-1}$ is the inverse of the distribution of a univariate $t$ distribution, $\rho$ is the correlation coefficient of the bivariate $t$ distribution when $g>2$, and $g$ is the degrees of freedom. As long as $\rho \neq 1$, tail dependencies will exist.

A positive dependence can be observed when stock returns and changes in trading volume move in the same direction. Therefore, it may not be adequate to claim that both stock price and trading volume increase when only a positive dependence from the Student's $t$ copula is observed, because a positive dependence could also come from a downward movement of both stock price and trading volume. To address this problem, we included the Gumbel copula to focus on the upper tail dependence and the Clayton copula to focus on the lower tail dependence. Thus, when a positive dependence from the Student's $t$ copula is observed, a positive dependence from the Gumbel copula during the same period is necessary to claim that changes in trading volume and stock returns are moving upward. If a positive dependence from the Gumbel copula is not observed but a positive dependence from the Clayton copula is found, it can be concluded that both changes in trading volume and stock returns were moving downward. 
According to McNeil, Frey, and Embrechts (2005), the Gumbel copula is an appropriate model for measuring the upper tail dependence. The Gumbel copula can be described as:

$\mathrm{C}\left(M_{A_{i}}, M_{B_{i}}\right)=\exp \left[-\left\{\left(-\ln \left(M_{A_{i}}\right)^{\mathrm{\kappa}}+\left(-\ln \left(M_{B_{i}}\right)^{\mathrm{\kappa}}\right\}^{\frac{1}{\kappa}}\right]\right.\right.$

where $\kappa$ measures the degree of dependence between $\mathrm{A}$ and $\mathrm{B}$ with the range of $1 \leq \kappa<\infty$. To compare the degree of dependence, $\kappa$ is normalized by calculating $\left(2-2^{\frac{1}{\kappa}}\right)$; thus, the value of $\left(2-2^{\frac{1}{\kappa}}\right)$ is between 0 and 1 . Therefore, a perfect upper tail dependence between $\mathrm{A}$ and $\mathrm{B}$ exists when $\left(2-2^{\frac{1}{\kappa}}\right) \rightarrow 1$ while no upper tail dependence between $\mathrm{A}$ and $\mathrm{B}$ exists when $\left(2-2^{\frac{1}{\kappa}}\right)=0$. The lower tail dependence, on the other hand, can be determined by the Clayton copula, which is defined as

$\mathrm{C}\left(M_{A_{i}}, M_{B_{i}}\right)=\max \left[\left(M_{A_{i}}{ }^{-\psi}+M_{B_{i}}{ }^{-\psi}-1\right)^{\frac{-1}{\psi}}, 0\right], \psi \neq 0$

where $\psi$ is the parameter representing the strength of dependence between $\mathrm{A}$ and $\mathrm{B}$ within the range of 0 $<\psi<\infty$ or $-1 \leq \psi<0$. To limit the outcome within the range of 0 to $1, \psi$ is normalized by computing $2^{\frac{-1}{\psi}}$. Thus, A and B have perfect dependence when $2^{\frac{-1}{\psi}} \rightarrow 1 \quad(\psi \rightarrow \infty)$, and A and B lack dependence when $2^{\frac{-1}{\psi}} \rightarrow 0(\psi \rightarrow 0)$.

In this study, we employed a rolling window technique to estimate dynamic dependencies. Specifically, we used the data from the $1^{\text {st }}$ day to the $100^{\text {th }}$ day to evaluate the first copula dependence. Subsequently, we used the data from the $2^{\text {nd }}$ day to the $101^{\text {st }}$ day to evaluate the second dependence. This rolling window technique helps deliver a sequence of dependencies from the three copulas adopted in this study.

\section{DATA}

The data used in this study consisted of the adjusted daily closing prices and trading volumes of Delta Air Lines, United Airlines, and American Airlines. Based on Cox and Portes (1998), who indicated that using a shorter time horizon to analyze the potential effect of a merger in a highly regulated industry may result in estimation errors, we defined the sample period for each airline as one month before the announcement date to one month after the merger completion date. Such design is due to the fact that, in practice, most airline mergers begin with negotiations between the target and the acquirer. As the information is transmitted to the market, investors begin to incorporate their forecast into the trading, which makes the observation of the pre-announcement period meaningful. Given the timelines provided in Table 1, the sample period for Delta Air Lines ranged from March 14, 2008 to November 28, 2008. For United Airlines, the sample period ran from April 1, 2010 to September 27, 2010. Finally, for American Airlines, the sample period extended from January 14, 2013 to December 13, 2013. Table 2 reports the summary statistics for the periods examined.

According to Table 2, American Airlines exhibited the highest average daily stock return and trading volume change at $0.24 \%$ and $0.39 \%$, respectively. Such results may be due to the fact that the timing of the other two mergers either coincided with the period of the recent financial crisis or immediately followed the recession. Among the three airlines, Delta Air Lines had the highest volatility in stock return and American Airlines had the greatest shift in trading volume. Since skewness is a measure of symmetry and kurtosis is a measure regarding whether fat-tails exist in the data, the summary statistics reported in Table 2 shows that the changes in trading volume and stock returns were not symmetric and normally distributed. The p-values reported from the Jarque-Bera test also confirmed that neither stock returns nor trading volume changes were normally distributed, which justified the use of the GARCH-EVT-Copula framework in calibrating the dependencies. 


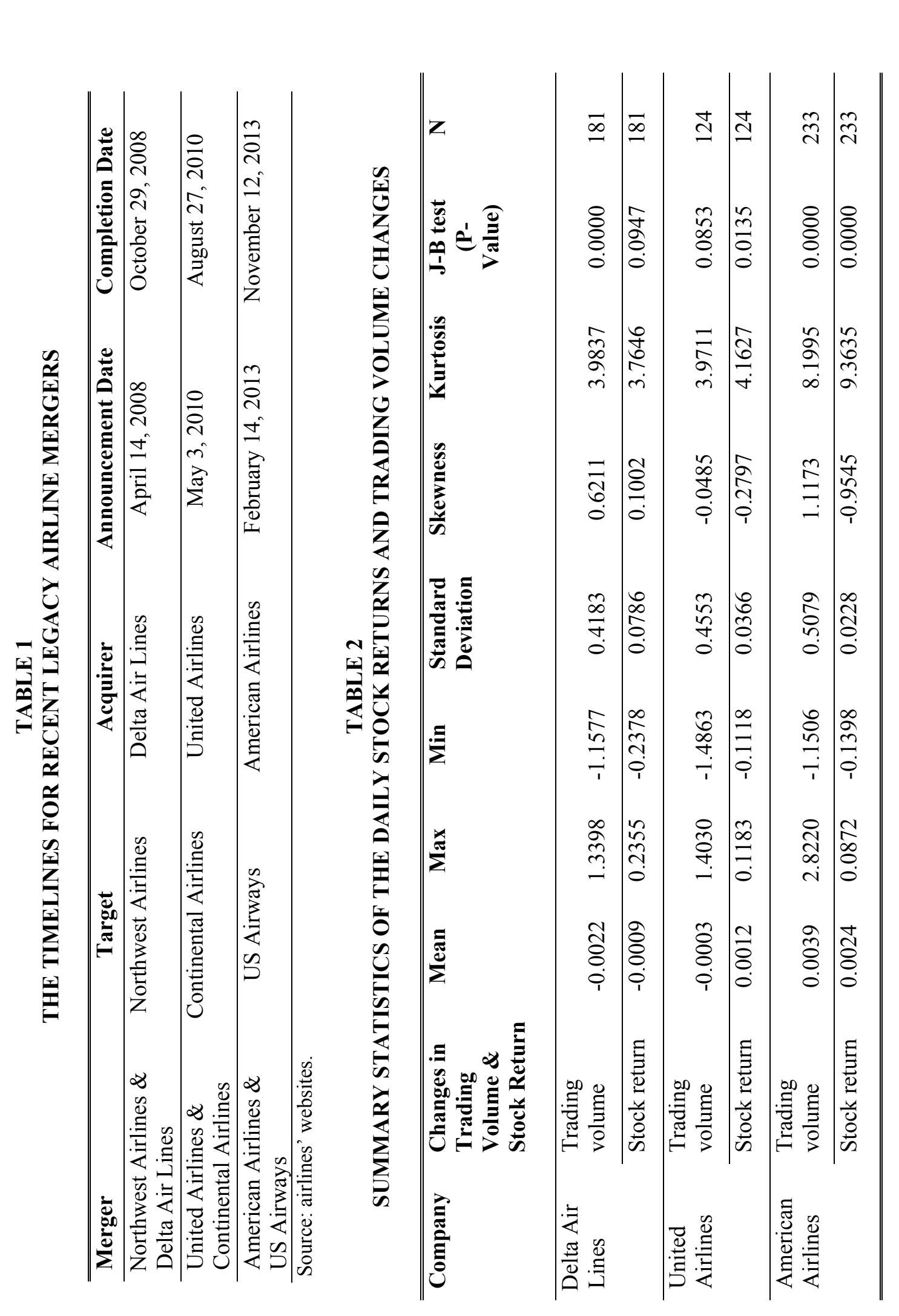

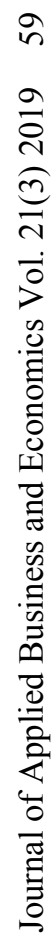




\section{EMPIRICAL RESULTS}

Table 3 reports the empirical dependencies between trading volume changes and stock returns for Delta Air Lines, United Airlines, and American Airlines. Figure 1, Figure 2, and Figure 3 illustrate the dynamics of the three copula dependencies calculated for Delta Air Lines, United Airlines, and American Airlines, respectively.

According to Table 3, Delta Air Lines has its highest Student's $t$ copula dependence at 0.2165 and the lowest at -0.1318 , with an average of 0.0237 . The maximum upper tail dependence observed from the Gumbel copula for Delta Air Lines was 0.2449, with the average at 0.1052. No lower tail dependencies were detected, as indicated by the results of the Clayton copula. As illustrated in Figure 1, for Delta Air Lines, the dependencies from the Student's $t$ copula and the Gumbel copula exhibited similar movements without significant Clayton copula dependencies. The theories suggest that significant positive dependencies from the Student's $t$ copula and significant dependencies from the Gumbel copula observed during the same period indicate that investors hold a favorable view of the stock. In the case of the merger between Delta Air Lines and Northwest Airlines, investors' positive perceptions were found for the following three periods: the month before the merger announcement, the month before the merger completion, and the month after the merger completion.

Concerning United Airlines, the maximum, minimum, and average dependencies derived from the Student's $t$ copula were $0.3300,-0.0166$, and 0.1141 , respectively. The maximum upper tail dependence observed from the Gumbel copula for United Airlines was 0.3160 , with the average at 0.1764 . The timevarying dependencies shown in Figure 2 revealed that investors were optimistic about the merger during most of the merger process. No lower tail dependencies, as estimated via the Clayton copula, were identified during the period investigated.

For American Airlines, the average dependency from the Student's $t$ copula was 0.1570 , with the maximum at 0.4166 and minimum at -0.0767 . The maximum upper tail dependence observed from the Gumbel copula for American Airlines was 0.3381, with the average at 0.1878. Some positive lower tail dependencies from the Clayton copula were observed just before the merger announcement, all of which were weaker compared to the Gumbel dependencies observed at the same time. Two peaks were associated with the Student's $t$ and Gumbel dependencies: the time around the merger announcement and the time around the merger completion. Both Student's $t$ and Gumbel copula dependencies were positive for most of the time observed, demonstrating that investors held a positive view of the merger during the course of the merger process.

A comparison of the three mergers revealed some interesting findings. First, despite the fact that airline mergers have been plagued by unsuccessful experiences (King et al., 2004; US GAO, 2010), our empirical results showed that investors had positive expectations of the recent three legacy airline mergers regardless of whether a merger took place during the bear market or bull market, as indicated by the joint appearance of positive Student's $t$ and Gumbel dependencies. These results reflect active investing in the acquiring company's stocks that triggered increases in stock prices and trading volumes. Moreover, for each merger, the positive dependencies from the Student's $t$ and Gumbel copulas tended to last for an extended period around the time of the merger announcement, the completion of the merger as defined by the approval of the merger from the authorities, and immediately after the merger completion. Therefore, the empirical results provide evidence that investors may see benefits as the merger progresses. Second, following this series of mega-mergers, the dependencies from the Student's $t$ and Gumbel copulas became stronger. The increasing dependencies could be due to the change in the state of the economy from the recession to expansion as well as to the formation of the oligopoly, which helped enhance acquiring companies' projected operational efficiency (Manuela, Rhoades, \& Curtis, 2016) and had a procompetitive effect on consumers (Carlton, Israel, MacSwain, \& Orlov, 2019) . 


\section{CONCLUSION}

This study examined whether investors held a favorable view of the recent legacy airline mergers by exploring the dynamic dependencies between daily stock returns and daily stock trading volume changes for the three US airlines: Delta Air Lines, United Airlines, and American Airlines. We assumed that if investors held a favorable view of a merger, a positive dependence between stock returns and trading volume changes would be observed during the merger period because investors would channel resources into the acquiring company, which would increase trading volume and stock prices. To better accommodate the nature of financial data that tend to deviate from the normality, we employed timevarying EVT-GARCH-Copula models to capture dynamic dependencies. The empirical results suggested that positive dependencies were observed beginning one month before the merger announcement to one month after the merger conclusion, indicating that investors were optimistic regarding the mergers and invested in the stocks of the acquiring companies. Mergers in the highly regulated airline industry are relatively complicated not only because the capital involved is immense, but also because of difficulties in integrations of labor workforce, operation systems, aircraft fleets, and approvals from authorities - all of which triggered uncertainty in post-merger prospects. Our research demonstrated that despite these obstacles, investors held favorable views of the recent legacy airline mergers. Future studies may explore whether investor expectations were subsequently confirmed by post-merger financial performance.

TABLE 3

\section{EMPIRICAL RESULTS}

\begin{tabular}{l|ccc}
\hline Delta Air Lines & Clayton & Gumbel & Student's $\boldsymbol{t}$ \\
\hline Maximum & 0.0000 & 0.2449 & 0.2165 \\
Minimum & 0.0000 & 0.0000 & -0.1318 \\
Average & 0.0000 & 0.1052 & 0.0237 \\
Standard Deviation & 0.0000 & 0.0681 & 0.0834 \\
Number of Dependence & 181 & 181 & 181 \\
\hline United Airlines & & Gumbel & Student's $\boldsymbol{t}$ \\
\hline Maximum & Clayton & 0.3160 & 0.3300 \\
Minimum & 0.0000 & 0.0548 & -0.0166 \\
Average & 0.0000 & 0.1764 & 0.1141 \\
Standard Deviation & 0.0000 & 0.0738 & 0.0808 \\
Number of Dependence & 0.0000 & 124 & 124 \\
& 124 & & Student's $\boldsymbol{t}$ \\
\hline American Airlines & & Gumbel & 0.4166 \\
Maximum & Clayton & 0.3381 & -0.0767 \\
Minimum & 0.1767 & 0.0668 & 0.1570 \\
Average & 0.0000 & 0.1878 & 0.1189 \\
Standard Deviation & 0.0114 & 0.0677 & 233 \\
Number of Dependence & 0.0283 & 233 & \\
& 233 & & \\
\hline Nots: & & &
\end{tabular}

Notes: The empirical dependencies from Clayton, Gumbel, and Student's $t$ copula models for Delta Air Lines, United Airlines, and American Airlines are reported in this table. 
FIGURE 1

DYNAMIC DEPENDENCIES OF CLAYTON, GUMBEL, AND STUDENT'S T COPULAS OF DELTA AIR LINES FOR THE PERIOD OF MARCH 14, 2008 TO NOVEMBER 28, 2008

Delta Air Lines

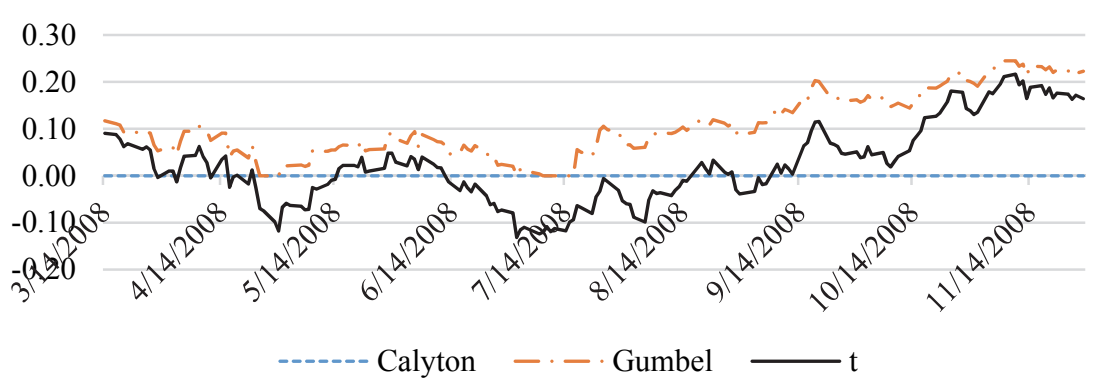

FIGURE 2

DYNAMIC DEPENDENCIES OF CLAYTON, GUMBEL, AND STUDENT'S T COPULAS OF UNITED AIRLINES FOR THE PERIOD OF APRIL 1, 2010 TO SEPTEMBER 27, 2010

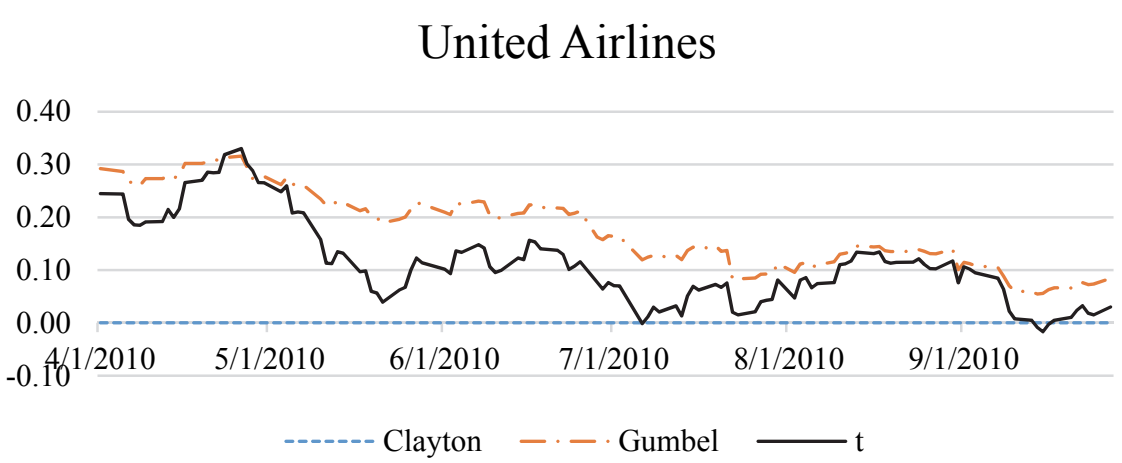

FIGURE 3

DYNAMIC DEPENDENCIES OF CLAYTON, GUMBEL, AND STUDENT'S T COPULAS OF AMERICAN AIRLINES FOR THE PERIOD OF JANUARY 14, 2013 TO DECEMBER 13, 2013

American Airlines

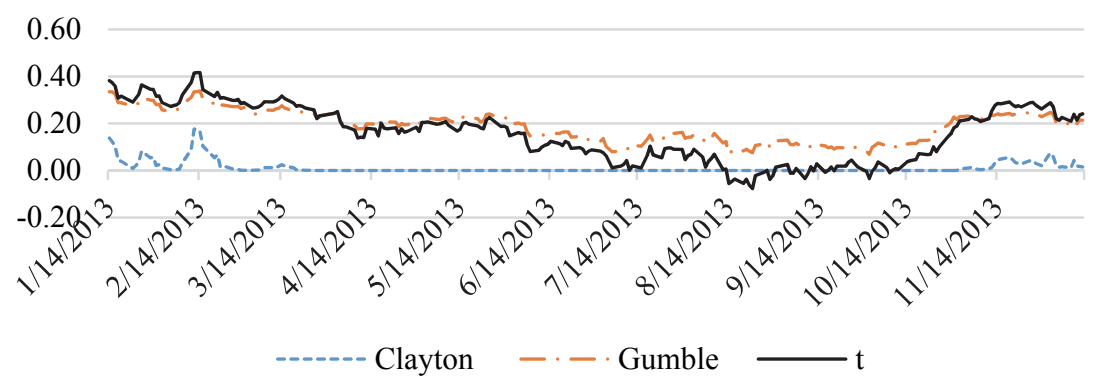




\section{REFERENCES}

Beirlant, J., Goegebeur, Y., Segers, J., \& Teugels, J. (2004). Statistics of Extremes: Theory and Applications. Wiley Publishing Co., West Sussex, England.

Berry, S., \& Jia, P. (2010). Tracing the woes: An empirical analysis of the airline industry. American Economic Journal: Microeconomics, 2, 1-43.

Brueckner J.K., \& Pels, E. (2005). European airline mergers, alliance consolidation, and consumer welfare. Journal of Air Transport Management, 11, 27-41.

Carlton, D., Israel, M., MacSwain, I., \& Orlov, E. (2019). Are legacy airline mergers pro- or anticompetitive? Evidence from recent U.S. airline mergers. International Journal of Industrial Organization, 62, 58-95.

Cortés, L., García, J., \& Agudelo, D. (2015). Effects of mergers and acquisitions on shareholder wealth: Event study for Latin American airlines. Latin American Business Review, 16(3), 205-226.

Cox, A. J., \& Portes, J. (1998). Mergers in regulated industries: The uses and abuses of event studies. Journal of Regulatory Economics, 14(3), 281-304.

Diana, T. (2011). Improving schedule reliability based on copulas: An application to five of the most congested US airports. Journal of Air Transport Management, 17(5), 284-287.

Embrechts, P., Lindskog, F., \& McNeil, A. (2003). Modelling dependence with copulas and applications to risk management In S. Rachev (Ed), Handbook of Heavy Tailed Distributions in Finance, 329384, Elsevier/North-Holland, Amsterdam.

Engle, R. (2002). Dynamic conditional correlation: a simple class of multivariate generalized autoregressive conditional heteroskedasticity models. Journal of Business and Economic Statistics, 20, 339-350.

Flouris, T., \& Swidler, S. (2004). American airlines' takeover of TWA: An ex-post analysis of financial market information. Journal of Air Transport Management, 10(3), 173-180.

Gong, S. X. H., \& Firth, M. (2006). The competitive effects of airline mergers and acquisitions: More capital market evidence. Journal of Air Transportation, 11(1), 88-105.

Hazel, R. (2018). Airline capacity discipline in the U.S. domestic market. Journal of Air Transport Management, 66, 76-86.

Hsu, C., Huang, C., \& Chiou, W. (2012). Effectiveness of copula-extreme value theory in estimating value-at-risk: Empirical evidence from Asian emerging markets. Review of Quantitative Finance and Accounting, 39, 447-468.

Hsu, C., \& Flouris, T. (2017). Comparing global airline merger experiences from a financial valuation perspective: An empirical study of recent European based airline mergers. Transportation Research Procedia, 25, 41-50.

Karpoff, J.M. (1987). The relation between price changes and trading volume: a survey. Journal of Financial and Quantitative Analysis, 22, 109-126.

Kawamori, T., \& Lin, M. H. (2013). Airline mergers with low cost carriers. Economics of Transportation, 2, 63-71.

Kim, E., \& Singal, V. (1993). Mergers and market power: Evidence from the airline industry. American Economic Review, 83, 549-569.

King, D.R., Dalton, D.R., Daily, C.M., \& Covin, J.G. (2004). Meta-analyses of post-acquisition performance: Indications of unidentified moderators. Strategic Management Journal, 25(2), 187200.

Manuela Jr., W. S., Rhoades, D. L., \& Curtis, T. (2016). The U.S. Airways Group: A post-merger analysis. Journal of Air Transport Management, 56, 138-150.

McNeil, A., Frey, R., \& Embrechts, P. (2005). Quantitative risk management: Concepts, techniques, and tools. Princeton University Press, Princeton.

Merkert, R., \& Morrell, P.S. (2012). Mergers and acquisitions in aviation - Management and economic perspectives on the size of airlines. Transportation Research Part E: Logistics and Transportation Review, 48, 853-862. 
Morrison, S. A. (1996). Airline mergers: A longer view. Journal of Transport Economics and Policy, 30 (3), 237-250.

Neftci, S. (2000). Value at risk calculations, extreme events, and tail estimation. Journal of Derivatives, 7 , 23-37.

Peters, C. (2006). Evaluating the performance of merger simulation: Evidence from the U.S. airline industry. Journal of Law and Economics, 49(2), 627-649.

Raghavan, V. (2013). Consolidation in the airline industry: The Delta-Northwest merger. Journal of International Finance and Economics, 13(2), 89-96.

Schosser, M., \& Wittmer, A. (2015). Cost and revenue synergies in airline mergers - Examining geographical differences. Journal of Air Transport Management, 47, 142-153.

Singal, V. (1996). Airline mergers and competition: An integration of stock and product price effects, Journal of Business, 69(2), 233-268.

Slovin, M., Sushka, M, \& Hudson, C. (1991). Deregulation, contestability, and airline acquisitions. Journal of Financial Economics, 30(2), 231-251.

Sklar, A. (1959). Fonctions de répartition à n dimensions et leurs marges. Publications de l'Institut de Statistique de L'Université de Paris, 8, 229-231.

United States Government Accountability Office. (2010). Airline Mergers. Issues Raised by the Proposed Merger of United and Continental Airlines. GAO-10-778T. Testimony before the Committee on Commerce, Science, and Transportation, U.S. Senate, Statement for the Record by Susan Fleming, Director, Physical Infrastructure Issues, May 27, 2010. 